\title{
Association Between Urinary Catecholamine Excretion and Urine Volume
}

\section{(ㄷ) (i) (우) $\Theta$}

\section{Authors}

Michael Haap, 2, Friedemann Blaschka², Rainer Lehmann², 4, Annika Hoyer³, 4, Karsten Müssig 4, 5, 6

\section{Affiliations}

1 Department of Internal Medicine, Medical Intensive Care Unit, University of Tübingen, Tübingen, Germany

2 Department of Internal Medicine, Endocrinology und Diabetology, Angiology, Nephrology and Clinical Chemistry, University of Tübingen, Tübingen, Germany

3 Institute for Biometrics and Epidemiology, German Diabetes Center, Leibniz Center for Diabetes Research at Heinrich Heine University Düsseldorf, Düsseldorf, Germany

4 German Center for Diabetes Research (DZD), München-Neuherberg, Germany

5 Division of Endocrinology und Diabetology, Faculty of Medicine, Heinrich Heine University Düsseldorf, Düsseldorf, Germany

6 Institute for Clinical Diabetology, German Diabetes Center, Leibniz Center for Diabetes Research at Heinrich Heine University Düsseldorf, Düsseldorf, Germany

Key words

epinephrine, norepinephrine, dopamine, homovanillylmandelic acid, metanephrine, normetanephrine, vanillylmandelic acid, pheochromocytoma, paraganglioma

received 20.11.2018

accepted $\quad 14.05 .2019$

Bibliography

DOI https://doi.org/10.1055/a-0926-3532

Published online: 7.6.2019

Horm Metab Res 2019; 51: 531-538

(c) Georg Thieme Verlag KG Stuttgart · New York ISSN 0018-5043

\section{Correspondence}

Karsten Müssig, MD

Division of Endocrinology and Diabetology

Faculty of Medicine, Heinrich Heine University Düsseldorf

Institute for Clinical Diabetology

German Diabetes Center

c/o Auf'm Hennekamp 65,

40225 Düsseldorf,

Germany

Tel.: +492113382 218, Fax: +492113382 690

karsten.muessig@ddz.de
Supplementary Material for this article is available online at http://www.thieme-connect.de/products.

\section{ABSTRACT}

Several confounders must be considered in the evaluation of urinary catecholamine excretion. However, literature is contradictory about potential confounders. The aim of the present study was to assess correlations between catecholamine excretion and anthropometric or clinical parameters with special attention to urine volume. A total of $96724-h$ urinary catecholamine measurements were performed in 593 patients for diagnostic purposes. The indication for urine examination was suspicion of secondary hypertension, phaeochromocytoma, or paraganglioma. From the patients examined, $57 \%$ were females and $43 \%$ were males. The patients' age ranged between 15 and 87 years with a median [Q1; Q3] of 51 [39; 62] years. Seventy-eight percent of the patients suffered from hypertension. Seventy percent of patients took one or more antihypertensive drugs. The most commonly used drugs were ACE inhibitors (43\%), while $\alpha$-blockers (15\%) were the least used drugs. Urinary excretion was between 500 and $11950 \mathrm{ml} / 24 \mathrm{~h}$ with a median of 2200 [1600;2685] ml/24 h. The median body mass index (BMI) was 26.7 [24.0;30.4] kg/m². The excretion of all catecholamines was greater in men than in women (all $p<$ $0.0001)$. Epinephrine $(p=0.0026)$, dopamine $(p<0.0001)$, and metanephrine $(p=0.0106)$ excretion decreased with age. BMI was associated with urinary excretion of dopamine $(p<0.0001)$, norepinephrine $(p=0.0026)$, normetanephrine $(p<0.0001)$, and homovanillylmandelic acid (HVMA; $p=0.0251)$. Urine volume correlated with urinary dopamine $(p=0.0127)$, metanephrine $(p<0.0001)$, normetanephrine $(p=0.0070)$, and HVMA $(p<0.0028)$ excretion. In addition to the established associations between urinary catecholamine excretion and age, gender, and BMI in the present study, urinary catecholamine excretion correlated also with urine volume. 


$\begin{array}{ll}\text { ABBREVIATIONS } \\ \text { ACE } & \text { Angiotensin-converting enzyme } \\ \text { AT1 } & \text { Angiotensin Il subtype 1 receptor } \\ \text { BC } & \text { Beta coefficient } \\ \text { BMI } & \text { Body mass index } \\ \text { Cl } & \text { Confidence interval } \\ \text { COMT } & \text { Catechol O-methyltransferase } \\ \text { HPLC } & \text { High performance liquid chromatography } \\ \text { HVMA } & \text { Homovanillylmandelic acid } \\ \text { PCA } & \text { Pheochromocytoma } \\ \text { PGL } & \text { Paraganglioma } \\ \text { VMA } & \text { Vanillylmandelic acid }\end{array}$

\section{Introduction}

Pheochromocytoma (PCA) or paraganglioma (PGL) are sporadic neuroendocrine tumors derived from cells of the adrenal medulla and paraganglia of the autonomic nervous system, respectively. The estimated incidence of PCA is approximately 0.8 per 100000 person years [1]. Clinical presentations with adrenergic symptoms include episodic tachycardia, paroxysmal hypertension, anxiety, headaches, and sweating [2]. These tumors may be identified via incidental discovery on imaging or by selective screening of persons at risk. PGL originating from the sympathetic paravertebral ganglia of the thorax, abdomen or pelvis produce frequently catecholamines like norepinephrine and dopamine, while PGL arising from parasympathetic ganglia of the head and neck usually do not produce catecholamines. Chromaffin cells of adrenal tumors produce both epinephrine and norepinephrine, which are metabolized to metanephrine and normetanephrine, respectively. Given that these metabolites are constantly produced from tumor cells [3], determination of catecholamines and their metabolites homovanilIylmandelic acid (HVMA), metanephrine, normetanephrine, and vanillylmandelic acid (VMA) plays an essential role in the diagnosis of catecholamine-producing tumors [4, 5]. In light of the high diagnostic validity of plasma normetanephrine and metanephrine in diagnosing PCA $[6,7]$, and, compared to urinary measurements, their more convenient determination and lack of inadvertent problems of accurate urine collection [8], the value of determination of urinary catecholamines and their metabolites has shortened in recent years.

In the diagnosis of pathological catecholamine production, the 24-h urine collection enables in particular determination of those hormones that are released in a pulsatile manner or attributed to a specific daily rhythm. However, these analyses can be influenced by several other factors like age [9], gender [10], body weight [9], smoking [11], eating habits, and the way of life [12], though the mentioned publications come to somehow contradictory results. The reasons for this may be that these papers differ significantly in terms of their study design, especially as regards sample composition and size as well as the use of exclusion criteria.

Previous work has shown an influence of urinary volume on the excretion of cortisone and cortisol $[13,14]$, whereas the possible influence of urine volume on catecholamine excretion has not been investigated in detail. In the present study comprising male and fe- male patients of all weight and age groups, urinary excretion of catecholamines and catecholamine decomposition products was investigated. In order to avoid a bias resulting from factors known to influence catecholamine excretion, strict exclusion criteria such as pathological laboratory values indicating acute or chronic disease or the use of medications interfering with catecholamine measurement were applied. The aim of the present study was to detect potential correlations between catecholamine excretion and anthropometric or clinical parameters such as age, gender, body mass index, blood pressure and, in particular, urine volume.

\section{Subjects and Methods}

In the period from 2005 to 2008 , urine was evaluated for catecholamines and catecholamine degradation products in 593 patients at the Medical Center Hospital at the University of Tübingen for diagnostic purposes. The indication for the urine examination was usually the suspicion of secondary hypertension or work-up of PCA or PGL. In addition to urinary catecholamine excretion, age, gender, body mass index, systolic and diastolic blood pressure, heart rate, diagnosis of arterial hypertension, and used anti-hypertensive drugs were documented.

Only patients with complete data sets and without exclusion criteria were included in the study. Since acute and chronic diseases may affect catecholamine excretion, patients with the following laboratory values were excluded from the study: creatinine $>1.5 \mathrm{mg} / \mathrm{dl}, \mathrm{C}$-reactive protein $(\mathrm{CRP})>5 \mathrm{mg} / \mathrm{l}$, hemoglobin $(\mathrm{Hb})<8 \mathrm{~g} / \mathrm{dl}$, aspartate aminotransferase (AST) $>100 \mathrm{U} / \mathrm{l}$, alanine aminotransferase (ALT) $>70 \mathrm{U} / \mathrm{l}$, and gamma-glutamyltransferase $(\gamma-G T)>120 \mathrm{U} / \mathrm{l}$. Patients already diagnosed with pheochromocytoma, as well as those with a suspected PCA (urinary catecholamines or their decomposition products $\geq$ double upper reference range) were also excluded from the study. Patients on medications that may interfere with catecholamine analysis were also excluded from the study. After application of these exclusion criteria, 593 patients with complete data sets remained in the study. In these patients, 967 24-hour urine samples were available for analysis. The numbers of urinary catecholamine measurements per visit are summarized in (Supplementary $>$ Tables 15 and 2S).

\section{Urine analysis}

Urine was collected over a 24-h time period in an acidified urine container. To avoid sampling errors, the patients received written instructions for 24-h urine collection. The concentrations of epinephrine, norepinephrine, dopamine, HVMA, metanephrine, normetanephrine, and VMA were quantified by high performance liquid chromatography (HPLC) using an internal standard for calibration and subsequent quantification. Commercial kits were used for the analyses of all compounds of interest (Kits No 6000, 1000B, and 2020 Chromsystems, Grafelfingen, Germany). Before sample preparation, the $\mathrm{pH}$ of the urines were adjusted [15]. The catecholamines and their metabolites were separated from the urine matrix prior to chromatographic separation by solid phase extraction on an ion exchange matrix [16]. After sample pretreatment, an isocratic HPLC analysis was performed applying a flow rate of $1 \mathrm{ml} / \mathrm{min}$ and a total run time of $20 \mathrm{~min}$. The electrochemical detection offers high sensitivity and selectivity due to the limited number of 
chemical structures and functional groups accessible to a redox process at a given work potential [17]. The limit of detection (LOD) for epinephrine, norepinephrine and dopamine is $3 \mu \mathrm{g} / \mathrm{l}$ and the linearity range covers $3-1000 \mu \mathrm{g} / \mathrm{l}$. The LOD for HVMA and VMA is $0.5 \mathrm{mg} / \mathrm{l}$ and the linearity range is $75 \mathrm{mg} / \mathrm{l}$ and $50 \mathrm{mg} / \mathrm{l}$, respectively. The LOD for metanephrine and normetanephrine is $5 \mu \mathrm{g} / \mathrm{l}$ and the linearity range reaches up to $5000 \mu \mathrm{g} / \mathrm{l}$. The intra-assay coefficients of variation (CV) for all detected compounds are below $5 \%$ and the inter-assay $C V s<6 \%$.

The reference ranges for urinary catecholamines were provided by the company producing the HPLC-kit (Chromsystems). They are based on the publication of Ross and colleagues [18]. Ross et al. used data for reference range determination of urinary free catecholamine from a HPLC analysis with electrochemical detection of the 24-h urine of 106 patients. The patients were suspected of having a PCA, but the diagnosis was subsequently rejected. The reference ranges for urinary metanephrines were also provided by Chromsystems. They are based on the publication in the text book L. Thomas (ed.): Labor und Diagnose, chapter 32 [19].

\section{Statistical analysis}

Continuous and discrete variables were described using means and standard deviations or percentages, respectively. Due to repeated 24-h-urinary catecholamine measurements, linear mixed models with random intercepts were used to estimate associations be-

- Table 1 Patients' characteristics $(n=593)$.

\begin{tabular}{|l|l|}
\hline Variables & Values \\
\hline Age (years) & $51[39 ; 62]$ \\
\hline Gender (female/male) & $338 / 255$ \\
\hline Body mass index $\left(\mathrm{kg} / \mathrm{m}^{2}\right)$ & $26.7[24.0 ; 30.4]$ \\
\hline Systolic blood pressure $(\mathrm{mmHg})$ & $150[130 ; 170]$ \\
\hline Diastolic blood pressure $(\mathrm{mmHg})$ & $90[80 ; 100]$ \\
\hline Heart frequency (beats per minute) & $71[64 ; 79]$ \\
\hline Arterial hypertension & $459(78 \%)$ \\
\hline Number of antihypertensive drugs & $0-180(30 \%)$ \\
\hline & $1-147(25 \%)$ \\
\hline Alpha blockers & $2-104(18 \%)$ \\
\hline Urinary volume (ml) & $3-76(13 \%)$ \\
\hline ACE inhibitors & $4-43(7 \%)$ \\
\hline Beta blockers & $5-34(6 \%)$ \\
\hline Calcium channel blockers & $6-9(1 \%)$ \\
\hline Diuretics & $256(43 \%)$ \\
\hline AT1 receptor antagonists & $220(37 \%)$ \\
\hline & $185(31 \%)$ \\
\hline & $138(23 \%)$ \\
\hline & $92(16 \%)$ \\
\hline & $86(15 \%)$ \\
\hline
\end{tabular}

Data are shown as median [Q1; Q3] or numbers (percent). tween catecholamine measurements (as dependent variables) and independent variables, comprising age, gender, body mass index, systolic and diastolic blood pressure, as well as urinary volume. To account for the 7 hypotheses tested, a Bonferroni corrected $\alpha$-level of $<0.05 / 7=0.007142857$ was considered statistically significant. All analyses were performed using SAS 9.4 (SAS Institute, Cary, NC, USA).

\section{Results}

\section{Patients' characteristics}

- Table 1 describes the characteristics of the 593 patients at the first visit, of which $57 \%$ were females and $43 \%$ were males. The age of the patients ranged between 15 and 87 years and was on average 51 years. Median body mass index was $26.7 \mathrm{~kg} / \mathrm{m}^{2}$, ranging between 17.2 to $55.0 \mathrm{~kg} / \mathrm{m}^{2}$. Seventy-eight percent of the patients examined suffered from arterial hypertension. Median systolic blood pressure was $150 \mathrm{mmHg}$ and median diastolic blood pressure was $90 \mathrm{mmHg}$. Seventy percent of patients examined took one or more antihypertensive drugs, whereas $30 \%$ of patients were without antihypertensive medication. The most commonly used drugs were angiotensin-converting enzyme (ACE) inhibitors (43\% of cases), while $\alpha$-blockers (15\% of cases) were the least used drugs for treatment of hypertension. Other antihypertensive drugs used in the present study were beta blockers (37\% of cases), calcium channel blockers ( $31 \%$ of cases), diuretics ( $23 \%$ of cases), and angiotensin II subtype 1 receptor (AT1) antagonists (16\% of cases). Depending on the severity of hypertension, patients received 1 -fold ( $25 \%$ of patients), 2 -fold ( $18 \%$ of patients), 3 -fold ( $13 \%$ of patients), 4 -fold ( $7 \%$ of patients), 5 -fold ( $6 \%$ of patients), and up to 6 -fold ( $1 \%$ of patients) therapy. Urine volume ranged from 500 to $11950 \mathrm{ml} / 24 \mathrm{~h}$ with a median value of 2200 [1600; 2685] $\mathrm{ml} / 24 \mathrm{~h}$.

\section{Epinephrine excretion}

The linear mixed model analysis for epinephrine excretion showed a negative association between age and epinephrine excretion $(p=0.0026$, beta coefficient $(B C)-0.031$, confidence interval $(C I$ $-0.052 ;-0.011)$ ). Furthermore, an association between gender and epinephrine excretion was found with higher values in men ( $p=0.0001, \mathrm{BC}-1.89, \mathrm{Cl}-2.50 ;-1.29)$. While we found a clinically relevant association between systolic blood pressure and epinephrine excretion ( $p=0.0507, \mathrm{BC} 0.013, \mathrm{Cl}-0.00004 ; 0.027$ ), there was no association between body mass index $(p=0.108)$, diastolic blood pressure $(p=0.874)$, urine volume $(p=0.632)$ and epinephrine excretion ( $\triangleright$ Table 2 ).

\section{Dopamine excretion}

- Table 2 shows the linear mixed model analysis for dopamine excretion as the dependent variable. Age $(p=0.0001, B C-2.48, \mathrm{Cl}$ $-2.97 ;-2.00$ ) was negatively associated with dopamine excretion, whereas body mass index ( $p=0.0001, \mathrm{BC} 3.36, \mathrm{Cl} 2.06 ; 4.67)$ and urine volume $(p=0.0127, B C 0.0089, \mathrm{Cl} 0.0019 ; 0.016)$ correlated positively with dopamine excretion ( $\vee$ Fig. 1a), though the association between urine volume and dopamine excretion did not persist Bonferroni correction for multiple tests. Furthermore, an association between gender and dopamine excretion was found with 
- Table 2 Association between urinary dopamine, epinephrine, and norepinephrine excretion and age, gender, body mass index, blood pressure, and urinary volume.

\begin{tabular}{|l|l|r|}
\hline Parameter & Estimate & \\
\hline Dopamine & & \\
\hline Age & & $<\mathbf{0 . 0 0 1}$ \\
\hline Gender & $-2.48(-2.97 ;-2.00)$ & $<\mathbf{0 . 0 0 0 1}$ \\
\hline Body mass index & $3.36(2.06 ; 4.67)$ & $<\mathbf{0 . 0 0 0 1}$ \\
\hline Systolic BP & $-0.025(-0.34 ; 0.29)$ & 0.8758 \\
\hline Diastolic BP & $0.35(-0.26 ; 0.96)$ & 0.2578 \\
\hline Urinary volume & $0.0089(0.0019 ; 0.016)$ & 0.0127 \\
\hline Epinephrine & & \\
\hline Age & $-0.031(-0.052 ;-0.011)$ & $\mathbf{0 . 0 0 2 6}$ \\
\hline Gender & $-1.89(-2.50 ;-1.29)$ & $<\mathbf{0 . 0 0 0 1}$ \\
\hline Body mass index & $-0.044(-0.098 ; 0.0098)$ & 0.1083 \\
\hline Systolic BP & $0.013(-0.00004 ; 0.027)$ & 0.0507 \\
\hline Diastolic BP & $0.0021(-0.024 ; 0.028)$ & 0.8740 \\
\hline Urinary volume & $-0.00007(-0.00038 ; 0.00023)$ & 0.6329 \\
\hline Norepinephrine & & \\
\hline Age & $0.002(-0.11 ; 0.12)$ & 0.9737 \\
\hline Gender & $-11.18(-14.70 ;-7.66)$ & $<\mathbf{0 . 0 0 0 1}$ \\
\hline Body mass index & $0.49(0.17 ; 0.81)$ & $\mathbf{0 . 0 0 2 6}$ \\
\hline Systolic BP & $0.055(-0.021 ; 0.13)$ & 0.1566 \\
\hline Diastolic BP & $0.090(-0.058 ; 0.24)$ & 0.2334 \\
\hline Urinary volume & $0.00052(-0.0012 ; 0.0022)$ & 0.5416 \\
\hline & & \\
\hline
\end{tabular}

BP: Blood pressure. $p$-Values in bold type were significant after correction for multiple tests.

higher values in men ( $p=0.0001, B C-51.3, C l-65.9 ;-36.6)$. In contrast, there was no association between systolic blood pressure or diastolic blood pressure and dopamine excretion (both $\mathrm{p}>0.05$ ).

\section{Norepinephrine excretion}

As shown in $>$ Table 2 , the linear mixed model analysis for norepinephrine excretion as the dependent variable showed a positive association between body mass index ( $\mathrm{P}=0.0026, \mathrm{BC} 0.49, \mathrm{Cl} 0.17$; 0.81 ) and norepinephrine excretion. Additionally, an association between gender and norepinephrine excretion was found with higher values in men $(\mathrm{p}=0.001, \mathrm{BC}-11.18, \mathrm{Cl}-14.70 ;-7.66)$. For the other independent variables like age, systolic blood pressure, diastolic blood pressure and urine volume, however, no correlation with norepinephrine excretion was found (all p >0.05).

\section{Homovanillylmandelic acid (HVMA) excretion}

The linear mixed model analysis for HVMA excretion as the dependent variable showed a clinically relevant negative association with age $(p=0.0631, B C-0.019, C l-0.039 ;-0.001)$ and a positive association with body mass index $(p=0.0251, \mathrm{BC} 0.059, \mathrm{Cl} 0.0074$; $0.11)$ and urine volume ( $p=0.0028, \mathrm{BC} 0.00043, \mathrm{Cl} 0.00015$; 0.00072 ) ( $\vee$ Fig. 1b). Moreover, an association between gender and HVMA excretion was found with higher values in men ( $p=0.0484, B C 0.059, C l 0.0074 ; 0.11)$, though the associations of HVMA excretion with age and gender did not persist Bonferroni correction for multiple tests. The other independent variables like systolic and diastolic blood pressure revealed no associations with HVMA excretion (all p>0.05; > Table 3).

\section{Metanephrine excretion}

The linear mixed model analysis for metanephrine excretion showed a negative association with age $(p=0.0106, B C-0.39, \mathrm{Cl}$ $-0.69 ; 0.091)$ that did not persist Bonferroni correction for multiple tests and a positive association with urine volume $(p=0.0001$, $\mathrm{BC} 0.01110, \mathrm{Cl} 0.0068 ; 0.015)$ ( $\mathbf{F i g . ~ 1 c ) . ~ I n ~ a d d i t i o n , ~ a n ~ a s s o c i a - ~}$ tion between gender and metanephrine excretion was found with higher values in men $(p=0.0001, B C-32.6, C l-41.5 ;-23.7)$. The remaining independent variables systolic and diastolic blood pressure as well as body mass index showed no associations with metanephrine excretion (all p>0.05; > Table 3).

\section{Normetanephrine excretion}

The linear mixed model analysis for normetanephrine excretion as the dependent variable showed a clinically relevant positive association with age $(\mathrm{p}=0.0517, \mathrm{BC} 0.75, \mathrm{Cl}-0.0057 ; 1.51)$ and positive associations with body mass index $(\mathrm{p}=0.0001, \mathrm{BC} 5.31, \mathrm{Cl} 3.34$; 7.29), systolic blood pressure ( $p=0.0136, \mathrm{BC} 0.5977, \mathrm{Cl} 0.12$; 1.07 ), and urine volume ( $p=0.007, B C 0.015, C l 0.0042 ; 0.026)$, though the association between normetanephrine excretion and systolic blood pressure did not persist Bonferroni correction for multiple tests ( $>$ Fig. 1d). In addition, an association between gender and normetanephrine excretion was found with higher values in men ( $p=0.0001, \mathrm{BC}-47.0, \mathrm{Cl}-69.5 ; 24.5)$. There was no association between normetanephrine excretion and diastolic blood pressure ( $p>0.05$; $>$ Table 3$)$.

\section{Vanillylmandelic acid (VMA) excretion}

The linear mixed model analysis for VMA excretion as the dependent variable showed a clinically relevant association with body mass index ( $p=0.0656, \mathrm{BC} 0.024, \mathrm{Cl}-0.0015 ; 0.049)$. Furthermore, an association between gender and VMA excretion was found with higher values in men ( $p=0.0001, \mathrm{BC}-0.74, \mathrm{Cl}-1.03 ;-0.45)$. For the other independent variables age, urine volume, systolic and diastolic blood pressure, however, no association with VMA excretion was found (all p>0.05; > Table 3).

In order to account for the antihypertensive medication as a potential confounding factor, we performed an additional sensitive analysis. Also after including the number of antihypertensive drugs taken by the patients as well as its interaction with age in the mixed linear models the results were not changed relevantly (Supplementary $>$ Tables 35 and 4 S).

\section{Discussion}

In the present study, the influence of anthropometric and clinical parameters comprising age, gender, body mass index, blood pressure and urine volume on urinary catecholamine excretion was investigated. 

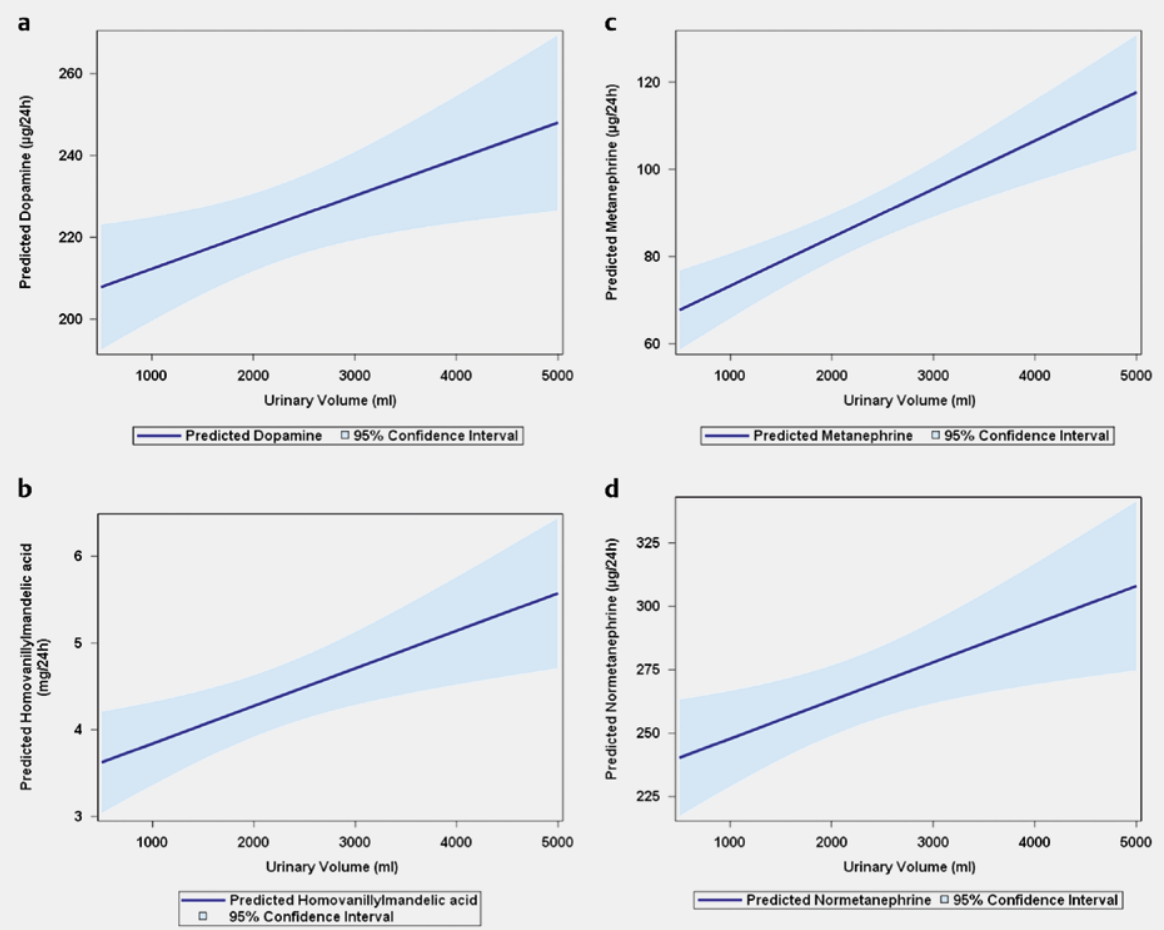

- Fig. 1 Predepicted urinary a dopamine, b homovanillylmandelic acid (HVMA), c metanephrine, and $\mathbf{d}$ normetanephrine excretion as a function of urine volume.

In contrast to previous studies, not only the catecholamines epinephrine, dopamine and norepinephrine were determined in 24-h urine samples, but also their metabolites HVMA, metanephrine, normetanephrine, and VMA.

Urine volume was positively associated with the excretion of dopamine, HVMA, metanephrine, and normetanephrine. In contrast, no association was found between urine volume and epinephrine, norepinephrine and VMA excretion. In agreement with our findings, Kawano et al., reported a positive association between 24-h urine volume and urinary dopamine excretion and no association between urine volume and epinephrine or norepinephrine excretion [20]. In contrast, early studies on catecholamine excretion in 24-h urine did not reveal a direct relationship between catecholamine excretion and urine volume [21-23]. Various reasons may have contributed to these contradictory results. In particular, the method used to determine urinary catecholamines has to be considered. For instance, a comparison between an immunological assay using monoclonal antibodies and an HPLC method showed only poor correlations between both methods [15]. Other factors which may influence urinary catecholamine excretion comprise smoking [9], environmental [10] and dietary factors. A higher salt intake increases urinary catecholamine excretion [24], whereas a low protein intake reduces the urinary excretion of dopamine [25]. None of the aforementioned studies has been controlled for these potential confounders.

In the present study, gender differences were found for the excretion of all catecholamines, with higher levels in men, in agreement with 2 previous studies showing greater excretion of all 3 cat- echolamines in men than in women $[10,26]$. However, according to the results of the present study, this applies not only to epinephrine, dopamine and norepinephrine, but also to their metabolites HVMA, metanephrine, normetanephrine and VMA which have not been tested by the 2 previous studies. There are further differences between the present work and the studies by Gerlo et al. and Lakatua et al. In the study by Gerlo et al., the number of included individuals was larger with 956 patients. However, the exclusion criteria were less strict. For instance, patients with PCA were not excluded. As a measure of the severity of concomitant disease only the criterion of intensive care treatment was used. In contrast, in the present work, several pathological laboratory parameters indicating acute or chronic disease were applied. In the study by Lakatua et al., the sample size was smaller with 340 patients, comprising both children and adults. Exclusion criteria were not taken into account.

While the age-related differences in catecholamine excretion in children have been well documented by several studies [27-29], there is just little work on the same issue in adults $[10,28,30]$. Our findings showing a decrease of epinephrine and dopamine excretion with age and no age dependence for norepinephrine excretion are in line with previous studies [26, 29, 30]. In addition, HVMA excretion showed a clinically relevant negative association with age and metanephrine excretion was negatively associated with age, whereas normetanephrine excretion demonstrated a clinically relevant positive association with age. There was no association between age and VMA excretion. Urinary excretion of dopamine is predominantly formed by decarboxylation of plasma l-dopa in the kidney [31, 32]. In rats, an age-depend- 
- Table 3 Association between urinary metanephrine, normetanephrine, HVMA and VMA excretion and age, gender, body mass index, blood pressure, and urinary volume.

\begin{tabular}{|l|c|r|}
\hline Parameter & Estimate & P \\
\hline Metanephrine & & \\
\hline Age & $-0.39(-0.69 ; 0.091)$ & 0.0106 \\
\hline Gender & $-32.6(-41.5 ;-23.7)$ & $<\mathbf{0 . 0 0 0 1}$ \\
\hline Body mass index & $-0.70(-1.47 ; 0.08)$ & 0.0788 \\
\hline Systolic BP & $0.15(-0.042 ; 0.33)$ & 0.1269 \\
\hline Diastolic BP & $-0.006(-0.36 ; 0.35)$ & 0.9732 \\
\hline Urinary volume & $0.011(0.0068 ; 0.015)$ & $<\mathbf{0 . 0 0 0 1}$ \\
\hline Normetanephrine & & \\
\hline Age & $0.75(-0.0057 ; 1.51)$ & 0.0517 \\
\hline Gender & $-47.0(-69.5 ; 24.5)$ & $<\mathbf{0 . 0 0 0 1}$ \\
\hline Body mass index & $5.31(3.34 ; 7.29)$ & $<\mathbf{0 . 0 0 0 1}$ \\
\hline Systolic BP & $0.60(0.12 ; 1.07)$ & 0.0136 \\
\hline Diastolic BP & $-0.077(-0.97 ; 0.81)$ & 0.8646 \\
\hline Urinary volume & $0.015(0.0042 ; 0.026)$ & $\mathbf{0 . 0 0 7 0}$ \\
\hline Homovanillylmandelic acid & \\
\hline Age & $-0.019(-0.039 ;-0.001)$ & 0.0631 \\
\hline Gender & $-0.61(-1.21 ;-0.0043)$ & 0.0484 \\
\hline Body mass index & $0.059(0.0074 ; 0.11)$ & 0.0251 \\
\hline Systolic BP & $0.0016(-0.013 ; 0.016)$ & 0.8286 \\
\hline Diastolic BP & $0.0043(-0.023 ; 0.032)$ & 0.7572 \\
\hline Urinary volume & $0.00043(0.00015 ; 0.00072)$ & $\mathbf{0 . 0 0 2 8}$ \\
\hline Vanillylmandelic acid & & 0.4953 \\
\hline Age & $0.0053(-0.0045 ; 0.015)$ & 0.0656 \\
\hline Gender & $-0.74(-1.03 ;-0.45)$ & 0.1476 \\
\hline Body mass index & $0.024(-0.0015 ; 0.049)$ & 0.5631 \\
\hline Systolic BP & $0.0049(-0.0017 ; 0.012)$ & \\
\hline Diastolic BP & $-0.0036(-0.016 ; 0.0087)$ & \\
\hline Urinary volume & $0.00049(-0.00009 ; 0.00019)$ & 0.001 \\
\hline
\end{tabular}

BP: Blood pressure. $\mathrm{p}$-Values in bold type were significant after correction for multiple tests.

ent rise in renal dopamine tissue levels has been described, which has been explained by an increasing synthesis $[33,34]$. Though the precise cause of the higher renal dopamine production in older age is unknown, it may be a feedback mechanism protecting against a diminishing function of the aging kidney [35]. However, despite increased dopamine tissue levels, dopamine excretion is reduced in older rats [33]. This result is consistent with the reduced dopamine excretion in the elderly shown in the present work.

In patients with chronic renal parenchymal damage, daily urinary excretion of levodopa oder L-DOPA, free dopamine, and dopamine metabolites correlates negatively with the degree of renal impairment [36]. The decreased dopamine excretion in renal insufficiency [37] may result from reduced activity of the renal dopaminergic system in chronic renal parenchymal disease [38]. The underlying pathophysiological mechanism is the progressive loss of tubular units which have the ability to synthesize dopamine from levodopa oder L-DOPA [39].

These findings are in line with our results. Though moderate to severe chronic kidney disease was an exclusion criterion, kidney function as assessed by serum creatinine levels correlated negatively with urinary dopamine excretion when adding serum creatinine to the linear mixed model analysis $(p<0.0001)$. On the other hand, in particular medications may influence dopamine secretion and may lead to increased levels. Drugs contributing to elevated dopamine levels comprise intravenous dopamine, levodopa oder L-DOPA, methyldopa, clozapine, antidepressants and metoclopramide and must, therefore, be taken into account when interpreting the data $[40,41]$.

In agreement with the present study in humans which found no age dependence for norepinephrine excretion, in a previous study in rodents, norepinephrine excretion was similar in 3-month-old and 12-month-old rats [33]. In contrast to neural cells, renal proximal tubule cells do not express dopamine hydroxylase, therefore renal dopamine is not converted to norepinephrine [42-44]. Given that norepinephrine is not produced in the kidney, decreasing renal function with age has no effect on norepinephrine excretion. However, investigations in mice showed a reduced synthesis of all catecholamines with increasing age in the adrenal glands [45]. In addition, mRNA expression levels of enzymes necessary for catecholamine synthesis, such as tyrosine hydroxylase, dopa decarboxylase, dopamine beta-hydroxylase, and phenylethanolamine N-methyltransferase, were diminished [45]. The cause of the constant norepinephrine excretion also in advanced age may be that only a small part of norepinephrine is produced in the adrenal medulla [27].

Ito et al. found positive correlations between systolic blood pressure and urinary excretion of dopamine, epinephrine, and norepinephrine [46], whereas diastolic blood pressure did not correlate with excretion of catecholamine metabolites [47]. In contrast, we did not detect associations between systolic blood pressure and urinary excretion of catecholamines or their metabolites, except for a clinically relevant association between systolic blood pressure and epinephrine excretion. In a previous dietary intervention study in rats, urinary catecholamines paralleled the changes in systolic and diastolic blood pressure, decreasing during calorie restriction and increasing during refeeding [48]. However, only epinephrine, norepinephrine and dopamine were studied. In a pilot study comprising 20 patients, urinary normetanephrine excretion correlated positively with systolic blood pressure, whereas urinary metanephrine excretion showed no correlation with systolic blood pressure [49]. The authors hypothesized that the sympathetic nervous system activity might affect systolic blood pressure variability. These results partially contradict our findings, except for the correlation between normetanephrine excretion and systolic blood pressure. This discrepancy may be due to the high percentage of patients (70\% of cases) taking at least one antihypertensive drug in the present study which might have attenuated the association between catecholamine excretion and systolic blood pressure.

With regard to a possible association between body weight and degree of activity of the sympathetic nervous system or catecholamine excretion, previous clinical studies have yielded different results. Some studies showed a positive correlation [16,50-54], others showed an inverse correlation $[55,56]$, and yet other studies showed no correla- 
tion $[9,28,57]$. The present study revealed positive correlations between norepinephrine and dopamine excretion and BMI and no correlation between epinephrine excretion and BMI. With the exception of metanephrine and VMA, which showed clinically relevant positive correlations, analyses of all other metabolites depicted significantly positive associations with body mass. Different reasons may have caused the discrepancies between our results and previous studies. First, various subtypes of obesity may exist which are not reflected by BMI alone [58]. Second, the samples of each study differ in terms of size and application of exclusion criteria. Third, excretion of urinary catecholamines was measured by different assays, with measurement of the activity of the sympathetic nervous system being difficult in general. The measurements of norepinephrine levels in plasma and urine as indices of the activity of the sympathetic nervous system are of limited sensitivity, since norepinephrine is not a circulating hormone, but is released locally by sympathetic nerve endings. Thus, moderate changes in sympathetic nervous system activity may not be detected in plasma or urine [59]. Because norepinephrine can also be produced in the adrenal glands in certain cases, it is difficult to distinguish whether norepinephrine comes from the sympathetic nervous system or adrenal nerve endings [59]. The results of the present work on the correlation between body mass and catecholamine excretion, however, are in line with previous studies showing that dietary weight loss as well as anorexia nervosa has a significant impact on catecholamine excretion $[54,60,61]$. Several approaches may serve to explain the increased catecholamine excretion in obese people: on the one hand hyperinsulinemia which is frequently found in obesity leads to a stimulation of the sympathetic nervous system [62], on the other hand, increased leptin levels have similar effects [63]. In obesity, leptin is increasingly released from fat cells in order to inhibit appetite-stimulating hormones. However, over time leptin resistance may develop resulting in attenuation of the leptin signaling. Furthermore, studies on the excretion of norepinephrine in obese humans showed a regional hyperactivity of the sympathetic nervous system in the kidneys [64].

Despite the strengths of our study, including the large number of measurements, the rigorous exclusion criteria, and the consideration of several potential confounding factors, there are also some limitations, such as the lacking correction of urinary catecholamines and their decomposition products by creatinine measurements. However, in order to avoid sampling errors, the patients received written instructions for $24-\mathrm{h}$ urine collections.

\section{Conclusion}

In addition to the well-established associations between urinary catecholamine excretion and age and gender and the more controversially discussed associations between urinary catecholamines and body mass index and blood pressure, in the present study, urinary catecholamine excretion were also associated with urine volume. This has to be considered as a potential influencing factor in the evaluation of urinary excretion levels of catecholamines and their respective degradation products.

\section{Conflict of Interest}

The authors declare that they have no conflict of interest.
References

[1] Beard CM, Sheps SG, Kurland LT et al. Occurrence of pheochromocytoma in Rochester, Minnesota, 1950 through 1979. Mayo Clin Proc 1983; 58: 802-804

[2] Pacak K, Linehan WM, Eisenhofer $G$ et al. Recent advances in genetics, diagnosis, localization, and treatment of pheochromocytoma. Ann Intern Med 2001; 134: 315-329

[3] Eisenhofer G, Keiser H, Friberg P et al. Plasma metanephrines are markers of pheochromocytoma produced by catechol-O-methyltransferase within tumors. J Clin Endocrinol Metab 1998; 83: 2175-2185

[4] Unger N, Pitt C, Schmidt IL et al. Diagnostic value of various biochemical parameters for the diagnosis of pheochromocytoma in patients with adrenal mass. Eur J Endocrinol 2006; 154: 409-417

[5] Eisenhofer G, Lenders JW, Pacak K. Choice of biochemical test for diagnosis of pheochromocytoma: Validation of plasma metanephrines. Curr Hypertens Rep 2002; 4: 250-255

[6] Eisenhofer G, Lenders JW, Linehan WM et al. Plasma normetanephrine and metanephrine for detecting pheochromocytoma in von Hippel-Lindau disease and multiple endocrine neoplasia type 2. N Engl J Med 1999; 340: 1872-1879

[7] Lenders JW, Pacak K, Walther MM et al. Biochemical diagnosis of pheochromocytoma: Which test is best? JAMA 2002; 287: 1427-1434

[8] Lenders JW, Duh QY, Eisenhofer $G$ et al. Pheochromocytoma and paraganglioma: An endocrine society clinical practice guideline. J Clin Endocrinol Metab 2014; 99: 1915-1942

[9] Jenner DA, Harrison GA, Prior IA et al. 24-h catecholamine excretion: Relationships with age and weight. Clin Chim Acta 1987; 164: 17-25

[10] Gerlo EA, Schoors DF, Dupont AG. Age- and sex-related differences for the urinary excretion of norepinephrine, epinephrine, and dopamine in adults. Clin Chem 1991; 37: 875-878

[11] Olsson T, Viitanen M, Hagg E et al. Catecholamine excretion in old age. Aging (Milano) 1991; 3: 263-268

[12] Jenner DA, Harrison GA, Prior IA et al. Inter-population comparisons of catecholamine excretion. Ann Hum Biol 1987; 14: 1-9

[13] Mericq MV, Cutler GB Jr. High fluid intake increases urine free cortisol excretion in normal subjects. J Clin Endocrinol Metab 1998; 83: 682-684

[14] Müssig K, Remer T, Fritsche A et al. Urinary free cortisone, but not cortisol, is associated with urine volume in severe obesity. Steroids 2009; 74: 742-745

[15] Peaston RT, Weinkove C. Measurement of catecholamines and their metabolites. Ann Clin Biochem 2004; 41: 17-38

[16] Smedes F, Kraak JC, Poppe H. Simple and fast solvent extraction system for selective and quantitative isolation of adrenaline, noradrenaline and dopamine from plasma and urine. J Chromatogr 1982; 231: 25-39

[17] Bicker J, Fortuna A, Alves G, Falcao A. Liquid chromatographic methods for the quantification of catecholamines and their metabolites in several biological samples--a review. Anal Chim Acta 2013; 768: 12-34

[18] Ross GA, Newbould EC, Thomas J et al. Plasma and 24 h-urinary catecholamine concentrations in normal and patient populations. Ann Clin Biochem 1993; 30: (Pt 1) 38-44

[19] Thomas L, Phäochromozytom, Paragangliom, Neuroblastom. In Thomas L. (ed). Labor und Diagnose : Indikation und Bewertung von Laborbefunden für die medizinische Diagnostik. 8th Edition Frankfurt/ Main: TH-Books Verlagsgesellschaft; 2012: 1769-1778

[20] Kawano Y, Kawasaki T, Kawazoe N et al. Circadian variations of urinary dopamine, norepinephrine, epinephrine and sodium in normotensive and hypertensive subjects. Nephron 1990; 55: 277-282 
[21] Von Euler US, Hellner-Bjorkman S, Orwen I. Diurnal variations in the excretion of free and conjugated noradrenaline and adrenaline in urine from healthy subjects. Acta Physiol Scand Suppl 1955; 33: 10-16

[22] Hoeldtke RD, Martin WR. Urine volume and catecholamine excretion. J Lab Clin Med 1970; 75: 166-174

[23] De Schaepdryver AF, Leroy JG. Urine volume and catecholamine excretion in man. Acta Cardiol 1961; 16: 631-638

[24] Boren DR, Henry DP, Selkurt EE et al. Renal modulation of urinary catecholamine excretion during volume expansion in the dog. Hypertension 1980; 2: 383-389

[25] Hathaway PW, Brehm ML, Clapp JR et al. Urine flow, catecholamines, and blood pressure. The variability of response of normal human subjects in a relaxed laboratory setting. Psychosom Med 1969; 31: 20-30

[26] Lakatua DJ, Nicolau GY, Bogdan C et al. Chronobiology of catecholamine excretion in different age groups. Prog Clin Biol Res 1987; 227B: $31-50$

[27] Dalmaz Y, Peyrin L, Sann L et al. Age-related changes in catecholamine metabolites of human urine from birth to adulthood. J Neural Transm 1979; 46: 153-174

[28] Moyer TP, Jiang NS, Tyce GM et al. Analysis for urinary catecholamines by liquid chromatography with amperometric detection: Methodology and clinical interpretation of results. Clin Chem 1979; 25: 256-263

[29] Premel-Cabic A, Turcant A, Allain P. Normal reference intervals for free catecholamines and their acid metabolites in 24-h urines from children, as determined by liquid chromatography with amperometric detection. Clin Chem 1986; 32: 1585-1587

[30] Descovich GC, Montalbetti N, Kuhl JF et al. Age and catecholamine rhythms. Chronobiologia 1974; 1: 163-171

[31] Brown M], Allison DJ. Renal conversion of plasma DOPA to urine dopamine. Br J Clin Pharmacol 1981; 12: 251-253

[32] Chugh G, Pokkunuri I, Asghar M. Renal dopamine and angiotensin II receptor signaling in age-related hypertension. Am J Physiol Renal Physiol 2013; 304: F1-F7

[33] Armando I, Nowicki S, Aguirre J et al. A decreased tubular uptake of dopa results in defective renal dopamine production in aged rats. Am J Physiol 1995; 268: F1087-F1092

[34] Vieira-Coelho MA, Hussain T, Kansra V et al. Aging, high salt intake, and renal dopaminergic activity in Fischer 344 rats. Hypertension 1999; 34: 666-672

[35] Choudhury D, Levi M. Kidney aging - inevitable or preventable? Nat Rev Nephrol 2011; 7: 706-717

[36] Pestana M, Jardim H, Correia F et al. Renal dopaminergic mechanisms in renal parenchymal diseases and hypertension. Nephrol Dial Transplant 2001; 16 (Suppl 1): 53-59

[37] Quelhas-Santos J, Soares-Silva I, Fernandes-Cerqueira C et al. Plasma and urine renalase levels and activity during the recovery of renal function in kidney transplant recipients. Exp Biol Med (Maywood) 2014; 239: 502-508

[38] Zhang MZ, Harris RC. Antihypertensive mechanisms of intra-renal dopamine. Curr Opin Nephrol Hypertens 2015; 24: 117-122

[39] Pestana M, Jardim H, Serrao P et al. Reduced urinary excretion of dopamine and metabolites in chronic renal parenchymal disease. Kidney Blood Press Res 1998; 21: 59-65

[40] Müssig K, Häring HU, Schleicher ED. Pseudopheochromocytoma in Parkinson's disease. Eur J Intern Med 2008; 19: 151-152

[41] Davidson DF. Elevated urinary dopamine in adults and children. Ann Clin Biochem 2005; 42: 200-207

[42] Asghar M, Tayebati SK, Lokhandwala MF et al. Potential dopamine-1 receptor stimulation in hypertension management. Curr Hypertens Rep 2011; 13: 294-302
[43] Felder RA, Jose PA. Mechanisms of disease: the role of GRK4 in the etiology of essential hypertension and salt sensitivity. Nat Clin Pract Nephrol 2006; 2: 637-650

[44] Zeng C, Jose PA. Dopamine receptors: Important antihypertensive counterbalance against hypertensive factors. Hypertension 2011; 57: $11-17$

[45] Amano A, Tsunoda M, Aigaki T et al. Age-related changes of dopamine, noradrenaline and adrenaline in adrenal glands of mice. Geriatr Gerontol Int 2013; 13: 490-496

[46] Ito Y, Fujimoto Y, Obara T. The role of epinephrine, norepinephrine, and dopamine in blood pressure disturbances in patients with pheochromocytoma. World J Surg 1992; 16: 759-763 discussion 763-754

[47] Bravo EL, Tarazi RC, Gifford RW et al. Circulating and urinary catecholamines in pheochromocytoma. Diagnostic and pathophysiologic implications. N Engl J Med 1979; 301: 682-686

[48] Ernsberger P, Koletsky RJ, Kilani A et al. Effects of weight cycling on urinary catecholamines: Sympathoadrenal role in refeeding hypertension. J Hypertens 1998; 16: 2001-2005

[49] Coulson JM. The relationship between blood pressure variability and catecholamine metabolites: a pilot study. J Hum Hypertens 2015; 29: $50-52$

[50] Lee ZS, Critchley JA, Tomlinson B et al. Urinary epinephrine and norepinephrine interrelations with obesity, insulin, and the metabolic syndrome in Hong Kong Chinese. Metabolism 2001; 50: 135-143

[51] Macdonald IA, Lake DM. An improved technique for extracting catecholamines from body fluids. J Neurosci Methods 1985; 13 : 239-248

[52] Paffenbarger RS Jr., Hyde RT, Wing AL et al. Physical activity, all-cause mortality, and longevity of college alumni. N Engl J Med 1986; 314: 605-613

[53] Saprunova MM. [Daily catecholamine excretion in children suffering from constitutional, exogenous obesity]. Vopr Pitan 1980; 18-20

[54] Young JB, Troisi RJ, Weiss ST et al. Relationship of catecholamine excretion to body size, obesity, and nutrient intake in middle-aged and elderly men. Am J Clin Nutr 1992; 56: 827-834

[55] Linnoila M, Oliver ], Adinoff B et al. High correlations of norepinephrine, dopamine, and epinephrine and their major metabolite excretion rates. Arch Gen Psychiatry 1988; 45: 701-704

[56] Reynolds V, Jenner DA, Palmer CD et al. Catecholamine excretion rates in relation to life-styles in the male population of Otmoor, Oxfordshire. Ann Hum Biol 1981; 8: 197-209

[57] Horky K, Marek J, Kopecka J et al. Influence of age on orthostatic changes in plasma renin activity and urinary catecholamines in man. Physiol Bohemoslov 1975; 24: 481-488

[58] Landsberg L, Troisi R, Parker D et al. Obesity, blood pressure, and the sympathetic nervous system. Ann Epidemiol 1991; 1: 295-303

[59] Troisi RJ, Weiss ST, Parker DR et al. Relation of obesity and diet to sympathetic nervous system activity. Hypertension 1991; 17 : 669-677

[60] Johnston JL, Leiter LA, Burrow GN et al. Excretion of urinary catecholamine metabolites in anorexia nervosa: effect of body composition and energy intake. Am J Clin Nutr 1984; 40: 1001-1006

[61] Young JB, Landsberg L. Diet-induced changes in sympathetic nervous system activity: possible implications for obesity and hypertension. J Chronic Dis 1982; 35: 879-886

[62] Krieger DR, Landsberg L. Mechanisms in obesity-related hypertension: role of insulin and catecholamines. Am J Hypertens 1988; 1: 84-90

[63] Bell BB, Rahmouni K. Leptin as a Mediator of Obesity-Induced Hypertension. Curr Obes Rep 2016; 5: 397-404

[64] Corry DB, Tuck ML. Obesity, hypertension, and sympathetic nervous system activity. Curr Hypertens Rep 1999; 1: 119-126 